\title{
Táticas organizacionais; desenvolvimentista; conteúdos e informação; tendências integradoras: a socialização organizacional abordada sob quatro correntes distintas
}

\author{
MSc. Diego César Terra de ANDRADE - Instituto Federal de Educação, Ciência e Tecnologia do Sul \\ de Minas Gerais / Campus Pouso Alegre - diego.terra@ifsuldeminas.edu.br \\ DSc. Maria de Lourdes Souza OLIVEIRA - Universidade Federal de Lavras - julinet@ dae.ufla.br \\ DSc. Mônica Carvalho Alves CAPPELLE - Universidade Federal de Lavras - edmo@ dae.ufla.br \\ DSc. Luiz Marcelo ANTONIALLI - Universidade Federal de Lavras - 1mantonialli@uol.com.br \\ DSc. Kely César Martins de PAIVA - Faculdade Novos Horizontes - kely.paiva@unihorizontes.br
}

Recebido em: 04/10/2012 - Aprovado em: 15/12/2012 - Disponibilizado em: 30/12/2012

\begin{abstract}
Resumo: As pesquisas que buscam compreender o fenômeno da socialização do individuo, novo ou não, em seu contexto laboral vem aumentando. No escopo dessa discussão tem-se trabalhos sob quatro correntes distintas: a das táticas organizacionais; a desenvolvimentista; a dos conteúdos e da informação; e a das tendências integradoras. O objetivo desse ensaio teórico é colaborar com o embasamento capaz de auxiliar na elaboração de novas pesquisas e trabalhos, sobretudo no Brasil, onde há predomínio de estudos apenas sob um enfoque. Para tanto, efetuou-se revisão integrativa (integrative review) buscando sintetizar o conhecimento atual sobre socialização organizacional. $\mathrm{O}$ artigo encerra destacando a necessidade de pesquisas adicionais com vistas a melhor compreensão das questões relativas ao indivíduo e o local laboral.

Palavras chave: Socialização organizacional. Táticas organizacionais. Desenvolvimentista. Conteúdos e informação. Tendências integradoras.

\section{Organizational tactics; developmental; content and information; integrative trends: organizational socialization addressed under four distinct streams}

\begin{abstract}
The studies that seek to understand the phenomenon of socialization of the individual, young or not, in your workplace settings is increasing. In the scope of this discussion has work under four distinct streams: the organizational tactics, the developmental, and the content of the information, and integrative trends. The purpose of this essay is to collaborate with the theoretical foundation able to assist in the preparation of new research and studies, especially in Brazil, where there is a predominance of studies only focus on one. Therefore, we performed an integrative review seeking synthesize current knowledge on organizational socialization. The article concludes by highlighting the need for further research aimed at better understanding of issues relating to the individual and the local labor.

Keywords: Organizational socialization. Organizational tactics. Developmentalist. Content and information. Integrative tendencies.
\end{abstract}

\section{INTRODUÇÃO}

Nas últimas décadas, observa-se que a sociedade vem passando por inúmeras transformações decorrentes de um novo contexto econômico, político e social. Não obstante, as organizações vêm sendo obrigadas a repensar sua forma de agir, buscando inclusive compreender o fenômeno da socialização do individuo, novo ou não, em seu contexto laboral. Diante disso, Borges et al. (2010) afirmam que uma das respostas da Academia foi intensificar as pesquisas sobre socialização organizacional, como uma ferramenta capaz de auxiliar nos processos de gestão de pessoas.

Segundo Feldman (1976) e Shinyashiki (2000), o tema vem despertando o interesse de administradores, pesquisadores e outros profissionais há algum tempo. No entanto, no Brasil, os trabalhos ainda são insipientes.

Gontijo e Melo (2005) atentam que a socialização organizacional é tida como um processo, muitas vezes, complexo de ser descrito e conduzido, sobretudo pelo fato de envolver tanto elementos objetivos como 
subjetivos, com implicações na vida afetiva, educacional e profissional do trabalhador.

Assim, esta é uma justificativa ao presente ensaio, que foi elaborado (metodologia) a partir de uma revisão integrativa (integrative review). Esse modo de revisão, de acordo com Neuman (1997), é adequado quando o pesquisador busca sintetizar o conhecimento atual sobre determinado tópico. A delimitação dos artigos ocorreu por meio da escolha de trabalhos seminais na área, como por exemplo, Van Maanen (1989) e Chao et al. (1994). O objetivo aqui é colaborar com o embasamento teórico para a elaboração de novas pesquisas e trabalhos.

\section{SOCIALIZAÇÃO E SOCIALIZAÇÃO ORGANIZACIONAL}

Segundo Levy Junior (1973), a socialização é um processo contínuo no qual o indivíduo ao longo da vida aprende, identifica hábitos e valores característicos que o ajudam no desenvolvimento de sua personalidade e na integração ao seu grupo, tornando-o sociável. Hábitos e valores esses que não são inatos. Ainda para Levy Junior (1973, p. 60), “em estado de isolamento social, o indivíduo não é capaz de desenvolver um comportamento humano, pois esse deve ser aprendido ao longo de suas interações com os grupos sociais". Nesse sentido, Chanlat et al. (1996, p. 36) afirma que "o ser humano não vive em um círculo fechado, pois é na relação com o outro que o ego se constrói”.
Durkheim (1987) ressalta a importância da socialização ao mostrar que a sociedade só pode existir porque penetra no interior do ser humano, moldando sua vida, criando sua consciência, suas ideias e valores. Socializarse implica o desenvolvimento de uma identidade diferenciadora, ao mesmo tempo em que a inclusão sócio-histórica ao meio (construído) assemelha-se e identifica-se com os grupos de referência (BERGER; BERGER, 1977; BERGER; LUCKMANN, 2002, 2004; MARTIN-BARÓ, 1992; TORREGROSA; VILLANUEVA, 1984 apud BORGES et al., 2010). Tal processo, portanto, é dinâmico no sentido de que é contínuo e encerra a vivência de contradições existenciais. É um processo que se desenrola durante toda a vida do indivíduo (BORGES et al., 2010), ou seja, não é possível afirmar que ele possua um início, meio e fim.

Shinyashiki (2000) expõe que o processo de socialização não se restringe apenas ao período do desenvolvimento durante a infância e adolescência. Afirma ser até ingenuidade aceitar que, nessas fases, fosse possível proporcionar todo o aprendizado social que o indivíduo necessita para o desempenho de papéis na fase adulta e das inúmeras mudanças que ocorrem ao longo de sua vida. Corroborando, portanto, que a socialização é contínua e permanente e, de acordo com o ambiente em que a pessoa está convivendo, essa tende a ser influenciada e influenciar o seu meio. 
Ao longo do processo de desenvolvimento humano, o indivíduo participa de inúmeros grupos sociais. A socialização faz com que o ser adquira as normas definidoras dos critérios morais e éticos, conforme os padrões da sociedade em que está inserido. Nessa constante interação com o meio, o indivíduo vai internalizando crenças e valores, construindo padrões de comportamento próprios para interação em cada grupo. Borges e Albuquerque (2004 citados por BORGES et al., 2010) atentam que o caráter vinculante da socialização esta associado à história da sociedade na qual a pessoa está se socializando e almejando tornar algo possível.

Tais valores vão se consolidando e determinando suas escolhas, dentre elas, as escolhas profissionais. Esse mesmo processo revela-se crucial no contexto de uma organização. Ao ingressar em um novo grupo, o funcionário precisa ser apresentado aos valores, crenças, normas e práticas da organização, passando por uma fase de socialização que lhe permitirá articular-se com os processos de comunicação e de integração que permeiam o fazer coletivo (GONTIJO, 2005). É o que Berger e Luckmann (1985) classificam de socialização secundária, uma vez que para esses autores a socialização primária é aquela que o indivíduo experimenta na infância e em virtude da qual se torna membro da sociedade.

Dá-se o nome de socialização organizacional, de acordo com Shinyashiki
(2003), a maneira como a organização recebe os funcionários e os integra à sua cultura, seu contexto e sistema, para que eles possam comportar-se de maneira adequada às expectativas da organização. Já Schein (1982) observa que o uso do termo socialização organizacional pode estar associado ao processo no qual um novo membro aprende os sistemas de valores, as normas e os padrões de comportamento demandados por uma organização ou pelo grupo no qual está ingressando. Van Maanen (1989) define socialização organizacional como: o processo pelo qual o indivíduo aprende valores e normas de comportamentos esperados, que permitem a ele participar como membro de uma organização.

Nesse sentido, Oliveira, A. et al. (2008) expõem que o processo de socialização organizacional é bidirecional e recíproco. Bidirecional porque a adaptação é mútua, tendo em vista a busca de uma verdadeira simbiose entre as partes (organização/funcionário). E recíproca, pois cada parte atua sobre a outra.

Já em um entendimento mais amplo sobre a temática, Motta (1993) afirma ainda que a socialização organizacional é um processo contínuo que se inicia antes mesmo da entrada do indivíduo na empresa e continua durante toda a sua permanência na organização (MOTTA, 1993).

As pesquisas sobre a temática dividiram-se, cronologicamente, sob quatro correntes distintas: a das táticas 
organizacionais; a desenvolvimentista; a dos conteúdos e da informação; e a das tendências integradoras. Expostos nas seções seguintes.

\section{TÁTICAS ORGANIZACIONAIS}

Neste enfoque, a atenção centra-se nas ações da organização que visam a facilitar o processo de socialização dos indivíduos. Busca-se identificar as dimensões segundo as quais as táticas se diferenciam ou podem ser classificadas, bem como a que objetivos de gestão cada tipo de tática pode servir (BORGES et al., 2010).

Dentre os estudos dessa corrente, destaca se o trabalho de Van Maanen (1989) ${ }^{1}$. O autor apresenta sete estratégias de socialização (Quadro 1) empregadas pelas organizações que não são mutuamente excludentes e que, na prática, estão combinadas de diversas formas.

Quadro 1 - Estratégias de socialização empregadas pelas organizações

\begin{tabular}{|c|c|}
\hline \begin{tabular}{|l|} 
Estratégias \\
formais $\mathrm{e}$ \\
informais de \\
socialização
\end{tabular} & $\begin{array}{l}\text { O processo formal de socialização age } \\
\text { na preparação do novato para ocupar um } \\
\text { cargo específico na organização. Quanto } \\
\text { mais formal for o processo, mais o papel } \\
\text { de novato é segregado e especificado, e } \\
\text { maior a tensão, o que influencia as } \\
\text { atitudes e valores dos novatos. Em uma } \\
\text { atmosfera informal, não existe forma de } \\
\text { diferenciação e grande parte da } \\
\text { aprendizagem novato } \\
\text { necessariamente ocorre no interior das } \\
\text { redes sociais e das tarefas relacionadas } \\
\text { que envolvem sua posição. Dessa forma, } \\
\text { o processo formal de socialização é } \\
\text { apenas a primeira etapa da socialização. } \\
\text { A segunda etapa ocorre quando o novato } \\
\text { é colocado em sua posição } \\
\text { organizacional designada, devendo } \\
\text { aprender informalmente as práticas reais } \\
\text { em seu setor. }\end{array}$ \\
\hline \begin{tabular}{|l|} 
Estratégias \\
individuais e \\
coletivas de \\
socialização
\end{tabular} & $\begin{array}{l}\text { Na socialização coletiva, os novatos são } \\
\text { agrupados em conjunto para o início e } \\
\text { processados por um conjunto de } \\
\text { experiências idênticas, com resultados }\end{array}$ \\
\hline
\end{tabular}

\begin{tabular}{|c|c|}
\hline & $\begin{array}{l}\text { relativamente similares. Quando um } \\
\text { grupo é introduzido em um programa de } \\
\text { socialização, ele desenvolve quase } \\
\text { sempre uma consciência coletiva, o que } \\
\text { pode gerar certa incompatibilidade entre } \\
\text { os objetivos organizacionais e os do } \\
\text { grupo. As estratégias individuais } \\
\text { também geram mudanças, mas, quando } \\
\text { comparadas às coletivas, perdem em } \\
\text { termos de homogeneidade de resultados. } \\
\text { As mudanças são isoladas e dependem, } \\
\text { em grande parte, da relação estabelecida } \\
\text { entre o agente socializador e o novato. } \\
\end{array}$ \\
\hline $\begin{array}{l}\text { Estratégias } \\
\text { sequenciais e } \\
\text { não } \\
\text { sequenciais } \\
\text { de } \\
\text { socialização }\end{array}$ & 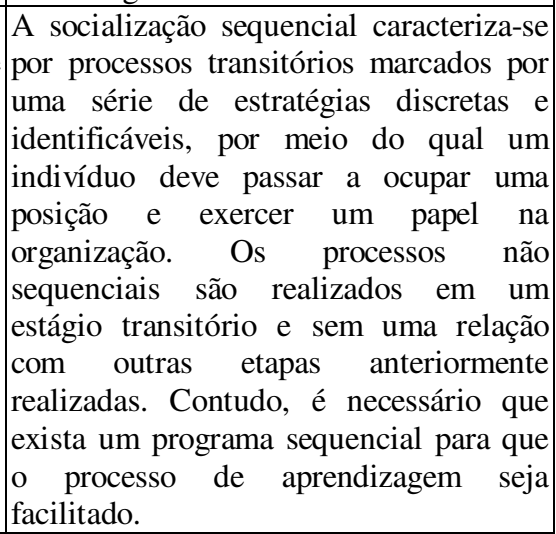 \\
\hline $\begin{array}{lr}\text { Estratégias } \\
\text { fixas } \\
\text { variáveis de } \\
\text { socialização }\end{array}$ & $\begin{array}{l}\text { Os processos fixos de socialização } \\
\text { proporcionam a um novato um } \\
\text { conhecimento preciso do tempo que } \\
\text { necessitará para completar determinado } \\
\text { estágio, ou seja, o tempo de transição é } \\
\text { padronizado. Nas estratégias de } \\
\text { socialização variáveis, os indivíduos } \\
\text { desconhecem a dimensão tempo do } \\
\text { período de transição. }\end{array}$ \\
\hline \begin{tabular}{|l|} 
Estratégias \\
de \\
socialização \\
por \\
competição \\
ou por \\
concurso
\end{tabular} & 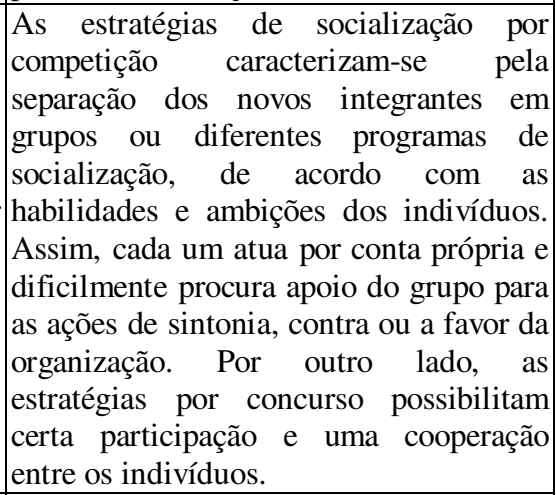 \\
\hline $\begin{array}{l}\text { Estratégias } \\
\text { de } \\
\text { socialização } \\
\text { em série } \\
\text { isoladas }\end{array}$ & $\begin{array}{l}\text { A estratégia de socialização em série é } \\
\text { aquela que prepara os novos integrantes } \\
\text { para assumir diversos papéis } \\
\text { organizacionais similares, sendo uma } \\
\text { garantia de que a organização não } \\
\text { sofrerá qualquer mudança ao longo do } \\
\text { tempo. Nas estratégias isoladas de } \\
\text { socialização, o indivíduo é socializado } \\
\text { com base em sua iniciativa e não por } \\
\text { qualquer padrão a ser seguido. Essa } \\
\text { estratégia apresenta um elevado risco, } \\
\text { pois o novo integrante poderá ficar } \\
\text { confuso e se perder durante o processo } \\
\text { de socialização. Entretanto, poderá }\end{array}$ \\
\hline
\end{tabular}




\begin{tabular}{|l|l|}
\hline & $\begin{array}{l}\text { também estimular a criatividade e a } \\
\text { iniciativa dos novos integrantes. }\end{array}$ \\
\hline $\begin{array}{l}\text { Estratégias } \\
\text { de } \\
\text { socialização } \\
\text { por meio de } \\
\text { investidura e estratégias objetivam confirmar ou } \\
\text { despojamento } \\
\text { destruir a identidade do novato na } \\
\text { organização. Ou seja, na investidura, } \\
\text { procura confirmar e estabelecer a } \\
\text { viabilidade e utilidade dos valores } \\
\text { pessoais dos novatos. Ele é bem-vindo } \\
\text { da forma como ele é. Já no processo de } \\
\text { despojamento, procura-se destruir e } \\
\text { despojar certos valores e crenças dos } \\
\text { novatos. Eles são, geralmente, } \\
\text { submetidos a uma série de "testes" } \\
\text { rigorosos para obter acesso privilegiado } \\
\text { na organização. Van Maanen (1989, p. } \\
\text { 60) ressalta que "as estratégias de } \\
\text { despojamento, no lugar das estratégias } \\
\text { de investiduras, provavelmente } \\
\text { produzem resultados similares entre os } \\
\text { novatos". }\end{array}$ \\
\hline
\end{tabular}

Fonte: adaptado de Van Maanen (1989)

As estratégias descritas, no quadro anterior, segundo Van Maanen (1989), são utilizadas pelas organizações para controlar e dirigir o comportamento de seus membros. $\mathrm{O}$ autor enfatiza, ainda, que grande parte do controle sobre o comportamento do indivíduo nas organizações é resultado direto da maneira pela qual a pessoa é socializada.

\section{ENFOQUE DESENVOLVIMENTISTA}

Segundo Borges et al. (2010), essa corrente mudou o foco de atenção das ações organizacionais para os processos cognitivos que os sujeitos da socialização organizacional vivenciam. Esse enfoque apresenta uma sequência de fases universais de desenvolvimento do processo de socialização nas organizações, de maneira a analisar as nuanças e ambiguidades da socialização.

O modelo descrito por Feldman (1976), denominado por Wanous (1992) como "modelo de três estágios de admissão" (Quadro 2) é um exemplo dessa corrente ${ }^{2}$.
Quadro 2 - Fases universais de desenvolvimento do processo de socialização nas organizações

\begin{tabular}{|c|c|}
\hline $\begin{array}{l}\text { Estágio } 1 \\
\text { Socialização } \\
\text { Antecipatória }\end{array}$ & $\begin{array}{l}\text { Este primeiro estágio compreende todo } \\
\text { o aprendizado que ocorre antes de o } \\
\text { novato entrar na organização. Nesse } \\
\text { caso, o indivíduo busca um conjunto de } \\
\text { informações sobre a organização e seu } \\
\text { possível trabalho, criando, também, } \\
\text { diversas expectativas. Dois fenômenos } \\
\text { ocorrem neste estágio: 1) realismo: grau } \\
\text { em que as expectativas dos indivíduos } \\
\text { formam um quadro completo e preciso } \\
\text { da vida organizacional. Indica o grau de } \\
\text { sucesso e de entendimento a respeito } \\
\text { das informações que foram transmitidas } \\
\text { no processo de recrutamento. 2) } \\
\text { congruência: grau em que as } \\
\text { competências e necessidades dos } \\
\text { indivíduos são compatíveis com as } \\
\text { exigências e recursos da organização. } \\
\text { Quanto mais as expectativas forem } \\
\text { realistas e congruentes, mais fácil será a } \\
\text { transição de fora para dentro da } \\
\text { organização. }\end{array}$ \\
\hline $\begin{array}{l}\text { Estágio } 2 \\
\text { Acomodação }\end{array}$ & 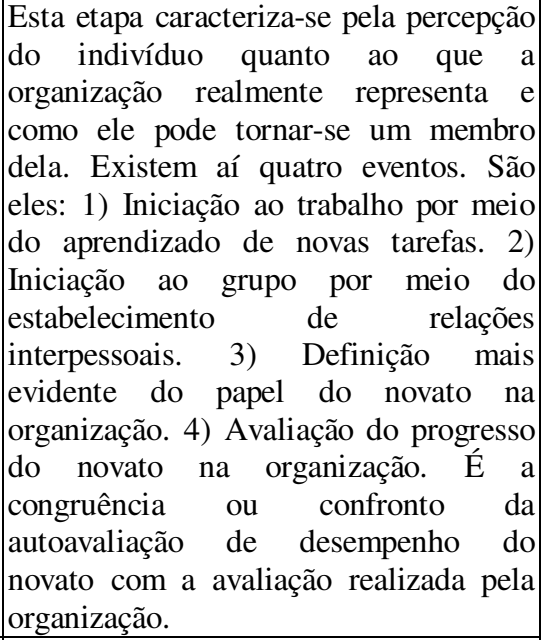 \\
\hline $\begin{array}{l}\text { Estágio } 3 \\
\text { Administração } \\
\text { do Papel }\end{array}$ & $\begin{array}{l}\text { Nesta etapa, os novatos necessitam } \\
\text { mediar os conflitos entre seu trabalho } \\
\text { no grupo e seu trabalho em outros } \\
\text { grupos, para o qual são demandados. } \\
\text { Dessa forma, dois tipos de conflitos } \\
\text { precisam ser administrados: conflitos } \\
\text { entre a vida profissional e a vida } \\
\text { familiar e conflitos entre o próprio } \\
\text { grupo de trabalho e outros grupos de } \\
\text { trabalho na organização. }\end{array}$ \\
\hline
\end{tabular}

Fonte: adaptado de Wanous (1992)

Cabe ressaltar, sob essa perspectiva, que, de acordo com Gontijo e Melo (2005), existem nuanças e ambiguidades na socialização organizacional. Por exemplo, o processo pode ser mais intenso no início da 
carreira de um indivíduo ou quando ele entra em uma empresa pela primeira vez, mas, de forma geral, observa-se que não existe, necessariamente, um fim para os eventos da socialização. Na verdade, a socialização pode ser contínua, mas não tão intensa, ao longo da vida de cada profissional (GONTIJO; MELO, 2005).

\section{ENFOQUE DOS CONTEÚDOS E DA INFORMAÇÃO}

De acordo com Borges et al. (2010), nesta corrente, a atenção se volta aos processos cognitivos do indivíduo, relacionando-os aos conteúdos do processo de socialização e ao papel da busca (pró) ativa de informações, abandonando a suposição de estágios sequenciais.

Oliveira, S. et al. (2008) afirmam que as pesquisas sob esse enfoque consideram a proatividade dos indivíduos, entendendo que os iniciantes em uma organização são agentes ativos que buscam as pessoas e os locais de aprendizado, julgados como valiosos para facilitar o próprio ajustamento, sendo capazes de influenciar as normas do grupo e os resultados de desempenho. Já com relação ao conteúdo e informação, as autoras afirmam que, de acordo com Ashforth et al. (2007), consiste em um conjunto de aspectos relacionados ao trabalho, os quais são considerados essenciais ao aprendizado de um indivíduo, para que esse possa se tornar um membro proficiente e se sentir confortável na organização. Ashforth et al. (2007) expõem que existe um conjunto de aspectos relacionados ao trabalho que são considerados essenciais ao aprendizado do funcionário, para que ele possa se tornar um membro capaz e, assim, se sinta adaptado à organização.

Nesse sentido, Carvalho (2009) afirma que o domínio das tarefas envolve fatores, como deveres e obrigações, responsabilidades, prioridades, modo de usar equipamentos e de lidar com questões de rotina. Os papéis de trabalho focam os limites da autoridade e da responsabilidade, as expectativas e os comportamentos adequados ao posto. Os processos de grupo referem-se à interação com os colegas, às normas e valores do grupo e à estrutura normativa do grupo de trabalho. Por fim, os atributos organizacionais dizem respeito às políticas, ao poder, ao conjunto de valores do sistema organizacional, à missão e ao estilo de liderança. Segundo a mesma autora, os resultados do estudo encampados sob esse enfoque indicaram, ainda, que a aquisição de informações sobre o domínio da tarefa, dos papéis e dos processos de grupo tende a ser mais importante durante as experiências iniciais no emprego do que a aquisição de informações relacionadas aos atributos organizacionais.

Oliveira, S. et al. (2008) afirmam que algumas das tipologias, nessa corrente, incluíram escalas para mensurar a aquisição de conteúdo. Carvalho (2009) cita alguns 
exemplos de trabalhos que incluem essas escalas, tais como:

a) Ostroff e Kozlowski (1992), que apresentaram uma medida de socialização organizacional que envolve quatro domínios de conteúdo: tarefas do emprego, papéis de trabalho, processos de grupo e atributos organizacionais.

b) Morrison (1995), para construir sua escala, integrou várias tipologias para derivar sete domínios de conteúdo (informação técnica sobre como executar as tarefas; informação de atribuições sobre as requisições e expectativas do papel de trabalho; informação social sobre outras pessoas e os relacionamentos com elas; informação avaliativa sobre como o desempenho e o comportamento estão sendo apreciados por outros na organização; informação normativa sobre a cultura organizacional; informação organizacional sobre a estrutura, procedimentos, produtos/serviços e resultados da empresa; e informação política sobre a distribuição de poder dentro da organização).

c) Taormina (1997) apresenta um modelo de socialização organizacional como um processo contínuo envolvendo quatro domínios, os quais, por sua vez, incluem quatro áreas de conteúdo que operam de forma contínua e interativa umas com as outras (treinamento; entendimento; suporte proporcionado por colegas de trabalho; e perspectivas de futuro). d) Haueter, Macan e Winter (2003) propõem a escala de três dimensões, a saber: organização, grupo, e tarefa.

Ademais, segundo Carvalho (2009), um dos mais conhecidos trabalhos ${ }^{3}$ sob esta corrente e tipologia é o de Chao et al. (1994). Esse autor defende a existência de seis domínios de conteúdo da socialização organizacional (Quadro 3).

Quadro 3 - Domínios de conteúdo da socialização organizacional

Proficiência delAvalia a extensão nas quais os desempenho indivíduos dominam suas tarefas.

\begin{tabular}{|c|c|}
\hline Pessoas & $\begin{array}{l}\text { Envolve a satisfação nas relações com } \\
\text { membros da organização. }\end{array}$ \\
\hline Políticas & $\begin{array}{l}\text { Abrange o sucesso de um indivíduo em } \\
\text { obter informações com respeito às } \\
\text { relações de trabalho formais e } \\
\text { informais e às estruturas de poder } \\
\text { dentro da organização. }\end{array}$ \\
\hline História & $\begin{array}{l}\text { Diz respeito ao conhecimento das } \\
\text { tradições, costumes, mitos e rituais que } \\
\text { compõem a cultura da organização. }\end{array}$ \\
\hline Linguagem & $\begin{array}{l}\text { Aborda o conhecimento do indivíduo } \\
\text { sobre a linguagem técnica profissional, } \\
\text { bem como a familiaridade com a } \\
\text { linguagem informal da organização. }\end{array}$ \\
\hline $\begin{array}{l}\text { Objetivos } \\
\text { valores } \\
\text { organizacio }\end{array}$ & $\begin{array}{l}\text { e Compreende a interiorização das regras } \\
\text { ou princípios que mantêm a integridade } \\
\text { da organização. }\end{array}$ \\
\hline
\end{tabular}

Fonte: adaptado de Chao et al. (1994)

Oliveira, S. et al. (2008) explicam ainda que Chao et al. (1994), em seus estudos, observaram também que, normalmente, as pessoas bem socializadas em seus papéis organizacionais têm maiores rendimentos pessoais, são mais satisfeitas, mais envolvidas com suas carreiras, mais adaptáveis e têm um melhor senso de identidade pessoal, comparativamente às menos socializadas.

É oportuno pontuar que no Brasil esta é a corrente predominante nos estudos sobre socialização organizacional. Sendo o trabalho 
e a escala de Chao et al. (1994), o mais influente deles. Como exemplo podem-se citar:

a) Borges, Ros e Tamayo (2001) em pesquisa realizada com amostra de trabalhadores, brasilienses, da construção civil e colaboradores de uma rede de supermercado. Sendo este o primeiro trabalho que visou traduzir e adaptar a escala de Chao et al. (1994) ao contexto brasileiro (OLIVEIRA, S. et al., 2008);

b) Oliveira, S. et al. (2008) em pesquisa realizada na Universidade Federal do Rio Grande do Norte, em 2005, com o objetivo de analisar a percepção dos servidores, da instituição, acerca do processo de socialização organizacional, segundo os grupos ocupacionais docentes e técnicoadministrativos. O trabalho foi desenvolvido com uma amostra de 524 indivíduos, quando fora aplicado um inventário composto de 54 itens. Cabe ressaltar que, segundo a autoras, este Inventário de Socialização Organizacional (ISO) é uma evolução ao questionário original de Chao et al. (1994), pois incorporou, da literatura, variáveis referentes a proatividade do individuo (OLIVEIRA, S. et al., 2008);

c) Borges et al. (2010), objetivou reconstruir e validar, por meio da técnica de análise fatorial (técnica dos eixos principais com rotação oblíqua), o ISO de 54 itens, ao setor público. A amostra foi composta de 903 servidores, de duas instituições, tendo sido encontrados sete fatores: Acesso às
Informações $(\alpha=0,78 ; \mathrm{r} 2=0,24)$; Competência e Proatividade $(\alpha=0,81 ; \mathrm{r} 2=$ $0,06)$; Integração com as Pessoas $(\alpha=0,81 ; \mathrm{r} 2$ $=0,06)$; Não Integração com a Organização $(\alpha=0,70 ; \quad$ r2 $=0,04) ;$ Qualificação Profissional $(\alpha=0,71 ; \mathrm{r} 2=0,03)$; Objetivos e Valores Organizacionais $(\alpha=0,81 ; \mathrm{r} 2=0,03)$; e Linguagem e Tradição $(\alpha=0,83 ; \mathrm{r} 2=0,03)$. O resultado deste trabalho foi um ISO composto de 45 itens validado e adaptado ao setor público brasileiro (BORGES et al. 2010);

d) Carvalho (2009), em sua tese de doutoramento, buscou analisar a relação entre a resiliência e a socialização organizacional dos novos servidores da Universidade Federal do Rio Grande do Norte (UFRN) e da Universidade Norueguesa de Ciência e Tecnologia (NTNU), confrontando os resultados obtidos numa perspectiva de análise transcultural. $\mathrm{O}$ trabalho utilizou o Inventário de Socialização Organizacional de 45 itens de Borges et al. (2010), que por hora encontrava-se no prelo (CARVALHO, 2009). Este trabalho resultou ainda em publicação na Revista de Administração Contemporânea (RAC), intitulado "Resiliência e Socialização Organizacional entre Servidores Públicos Brasileiros e Noruegueses" (CARVALHO et al. 2011) $)^{4}$.

e) Andrade (2011) realizou sua dissertação em uma Instituição Federal de Ensino Superior (Ifes), com os servidores técnico-administrativos e docentes, objetivando: identificar a percepção dos 
servidores acerca do nível de socialização organizacional; avaliar se há entre os servidores técnico-administrativos e docentes diferença no nível de socialização organizacional; verificar se o nível de socialização organizacional varia conforme o tempo de serviço na instituição; e observar se o nível de socialização organizacional varia quanto à lotação setorial/departamental. Sob o pano de fundo e justificativa deste trabalho, teve-se o aumento do número de servidores na Ifes, advindo de sua adesão ao Programa de Apoio a Planos de Reestruturação e Expansão das Universidades Federais - Reuni. A amostra foi composta de 285 membros e, também, foi utilizado o Inventário de Socialização Organizacional de 45 itens (ANDRADE, 2011).

\section{TENDÊNCIAS INTEGRADORAS}

Como o próprio nome explica, esta corrente integra as anteriores de forma tal a complementá-las, uma vez que estudos mais aprofundados não indicam que elas sejam excludentes umas às outras. Carvalho (2009) afirma a importância de se considerar diferentes variáveis para se ter uma compreensão mais ampla do fenômeno, o que fez com que as pesquisas em socialização organizacional passassem a ter desenhos mais abrangentes.

Borges et al. $(2010)^{5}$ corroboram com essa afirmação e expõem que as tendências integradoras partem do pressuposto de que as abordagens que as antecedem são complementares umas às outras, iluminando o processo considerando ângulos distintos. Tais tendências, além de integrarem as contribuições anteriores, ao refletirem sobre o processo, considerando vários níveis de análise, focalizam a importância de o processo ser compreendido no contexto e apresentam forte característica explicativa.

Carvalho (2009) destaca o estudo de Saks e Ashforth (1997), pesquisadores que, com a intenção de construir uma estrutura integrada para o estudo dessa maneira de enxergar o fenômeno, propuseram o denominado Modelo do Processo Multinível de Socialização Organizacional.

Segundo Carvalho (2009), esse modelo tem como foco a informação e a aprendizagem, pautando-se nos estudos que demonstraram que a socialização é primordialmente um processo de aprendizagem. O modelo parte da concepção de que uma diversidade de variáveis contextuais (extraorganizacionais, organizacionais, grupais e do posto de trabalho) podem influenciar os fatores de socialização, que se dividem em três grupos:

a) Organizacionais (táticas de socialização, programas de orientação, treinamento e tutorização);

b) Grupais (táticas de socialização, suporte social e aprendizagem social);

c) Individuais (táticas e comportamentos pró-ativos dos iniciantes).

Para finalizar esta etapa do trabalho, elaborou-se uma figura representativa (Figura 
1) acerca das diferentes abordagens da socialização organizacional, aqui apresentadas.

Figura 1 - Representação gráfica dos distintos enfoques dos estudos sobre socialização organizacional

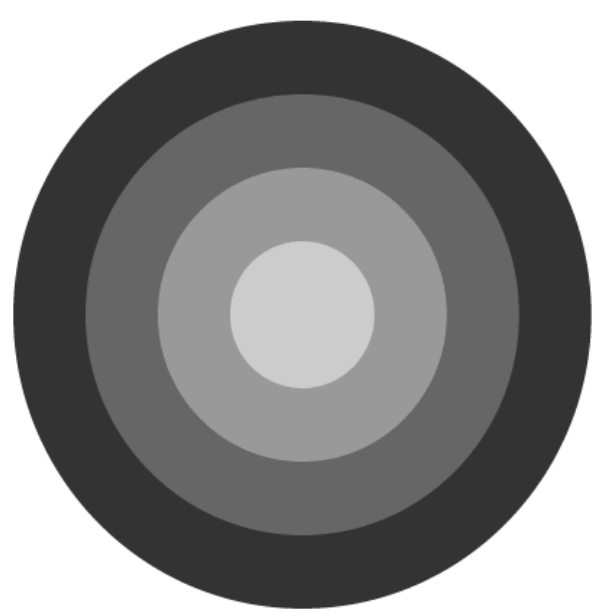

Táticas organizacionais - influência das açöes da organização no processo de social izaçăo dos indivíduos.

Enfoque desenvolvimentista - a iniciação de indivíduos na organização é passivel de ser entendida como um rito de passagem. Enfoque dos conteúdos e da informação - efeito das açóes e
percepçóes do indivíduo sobre o seu próprio ajuste na organização.

Tendências integradoras - integra os dois níveis de análise: individual e organizacional, assi m como variáveis de contexto e resultados.

Fonte: Elaborado pelos autores

Contudo, há a ciência de que a realidade não se "localiza" em uma dimensão de forma estanque. Cotidianamente, os processos de socialização podem abarcar aspectos de outras dimensões que não exclusivamente, por exemplo, a desenvolvimentista assim como se observa em outros trabalhos situados na Teoria das Organizações, onde "[...] nem sempre se tem plena consciência das tradições a que pertencemos [...]" (BURRELL; MORGAN, 1979, p. 1-2).

\section{CONCLUSÃO}

Espera-se que a contribuição prestada neste texto, que fora escrito por meio de uma revisão integrativa, possa fazer avançar as discussões sobre socialização organizacional, sob suas diferentes correntes teóricas na produção nacional. Foi com esse propósito que se buscou traduzir e condensar as ideias de diferentes autores para pensar o tema, bem como servir de referências a outros estudos. Com a consciência que tal esforço está apenas no início, pois, compreendem-se que as possibilidades de utilização sejam vastas. Aqui somente esboçou-se o básico sobre elas, tanto por falta de espaço, quanto por sua riqueza e dinâmica. De toda forma, acreditase firmemente que os estudos sobre o fenômeno da socialização organizacional seja uma forma válida e capaz de auxiliar na gestão de pessoas e, sobretudo, no entendimento de questões relativas ao indivíduo e o local laboral.

\footnotetext{
${ }^{1}$ Segundo Andrade (2011), autores como Allen (1990), Blau (1988), Jones (1986) e Van Maanen e Schein (1979) também tratam de socialização sob esse enfoque.

${ }^{2}$ Segundo Andrade (2011), autores como Blau (1988), Dubinsky et al. (1986), Feldman (1976,1980) e Nelson (1987) também tratam de socialização sob essa corrente. Gontijo e Melo (2005) citam, ainda, os trabalhos de Buchanan (1974), Porter-Lawler-Hackman (1975) e Van Gennep (1978).
}

${ }^{3}$ Segundo Andrade (2011), autores como Chao, Walz e Gardner (1992), Maier e Brunstein (2001), Major et al. (1995), Miller e Jablin (1991), Ostroff e Kozlowski (1995) e Setton e Adkins (1997) também tratam de socialização sob essa corrente

${ }^{4}$ Cabe ressaltar que os resultados das análises fatoriais $\left(r^{2}\right)$ e do Alpha de Cronbach $(\alpha)$ de Oliveira, S. et al. (2008), Carvalho (2009), Borges et al. (2010) e Carvalho et al. (2011) possuem os valores iguais, mesmo utilizando amostras distintas.

5 Segundo Andrade (2011), autores como Feldman e Tompson (1991), Griffin, Colella e Goparaju (2000) também tratam de socialização sob esse enfoque. 


\section{REFERÊNCIAS}

ANDRADE, D. C. T. Socialização organizacional em uma IFES Mineira em tempos de REUNI. 2011. 118p. Dissertação (Mestrado em Administração) - Universidade Federal de Lavras, Lavras, 2011.

ASHFORTH, B. E. et al. Socialization tactics, proactive behavior, and newcomer learning: Integrating socialization models. Journal of Vocational Behavior, Orlando, v. 70, n. 3, p. 447-462, June 2007.

BERGER, P. L.; LUCKMANN, T. A construção social da realidade: tratado de sociologia do conhecimento. Petrópolis: Vozes, 1985. 247 p.

BORGES, L. O. et al. Re-construção e validação de um inventário de socialização organizacional. Revista de Administração Mackenzie, São Paulo, v. 11, n. 4, p. 4-37, jul./ago. 2010.

BURRELL, G.; MORGAN, G. Sociological paradigms and organizational analysis. Aldershot: Ashgate, 1979. p. 1-5.

CARVALHO, V. D. Resiliência e socialização organizacional de novos servidores: um estudo transcultural. 2009. 272 p.Tese (Doutorado em Psicologia Social) - Universidade Federal do Rio Grande do Norte, Natal, 2009.

CARVALHO, V. D.; BORGES, L. O.; VIKAN, A.; HJEMDAL, O.. Resiliência e socialização organizacional entre servidores públicos brasileiros e noruegueses. Rev. adm. contemp. [online]. 2011, vol.15, n.5, pp. 815-833. ISSN 19827849 .

CHANLAT, J. F. et al. O indivíduo na organização: dimensões esquecidas. São Paulo: Atlas, 1996. 204 p.

CHAO, G. T. et al. Organizational socialization: its content and consequences. Journal of Applied Psychology, Washington, v. 79, n. 5, p. 730-743, Oct. 1994.
DURKHEIM, E. As regras do método sociológico as regras do método sociológico as regras do método sociológico. São Paulo: Companhia Editora Nacional, 1987. 1285 p.

FELDMAN, D. C. A contingency theory of socialization. Administrative Science Quarterly, Ithaca, v. 21, n. 3, p. 433-450, 1976.

GONTIJO, C. L. Socialização, cultura e constituição do sujeito organizacional: um estudo de caso. Gestão e Conhecimento, Poços de Caldas, v. 1, n. 1,p. 1-19, mar./jun. 2005.

GONTIJO, M. C. L.; MELO, M. Encontros e desencontros ao longo do processo de socialização organizacional de profissionais contratados por meio de programas de trainees. In: ENCONTRO ANUAL DA ASSOCIAÇÃO NACIONAL DE PÓSGRADUAÇÃO EM ADMINISTRAÇÃO, 29., 2005, Brasília. Anais... Brasília: ANPAD, 2005. 1 CD-ROM.

LEVY JUNIOR, M. Socialização. In: CARDOSO, F. H.; IANNI, O. (Org.). Homem sociedade. São Paulo: Editora Nacional, 1973. 318 p.

MORRISON, E. W. Information usefulness and acquisition during organizational encounter. Management Communication Quarterly, New York, v. 9, n. 2, p. 131-155, Nov. 1995.

MOTTA, F. C. P. Controle social nas organizações. Revista de Administração de Empresas, São Paulo, v. 33, n. 5, p. 68-87, set./out. 1993.

NEUMAN, L. W. Social research methods: qualitative and quantitative approaches. Boston: Allyn \& Bacon, 1997.

OLIVEIRA, A. A. R. et al. A prática da responsabilidade social através da socialização organizacional. In: ENCONTRO NACIONAL DE ENGENHARIA DE PRODUÇÃO, 18., 2008, Rio de Janeiro. 
Anais... Rio de Janeiro: ENEGEP, 2008.

Disponível em:

<http://www.abepro.org.br/biblioteca/enegep2

008_TN_STO_079_551_11827.pdf > . Acesso

em: 20 mar. 2011.

OLIVEIRA, S. D. C. et al. A socialização organizacional dos servidores da UFRN, segundo grupo ocupacional e tempo de serviço. Revista Psicologia, Florianópolis, v. 8, n. 1, p. 118-141, 2008.

OSTROFF, C.; KOZLOWSKI, S. W. J. Organizational socialization: the role of information acquisition. Personnel

Psychology, Washington, v. 45, n. 4, p. 849872, Dec. 1992.

SCHEIN, E. H. A psicologia organizacional. Rio de Janeiro: Prentice-Hall, 1982. 224 p.

SHINYASHIKI, G. T. O processo da socialização organizacional. In: FLEURY, M. T. As pessoas na organização. São Paulo:

Gente, 2003. p. 165-184.

SHINYASHIKI, G. T. O processo de socialização organizacional: um estudo de caso de trainees. 2000. 155 f. Tese (Doutorado em Administração) Universidade de São Paulo, São Paulo, 2000.

TAORMINA, R. J. Organizational socialization: a multidomain, continuous process models. International Journal of Selection and Assessment, New York, v. 5, n. 1, p. 29-47, Jan. 1997.

VAN MAANEN, J. Processando as pessoas estratégias de socialização organizacional. In: FLEURY, M. T. L.; FISCHER, R. M.

Cultura e poder nas organizações. São

Paulo: Atlas, 1989. cap. 2, p. 45- 62.

WANOUS, J. P. Organizational entry:

recruitment, selection, orientation and newcomers. Massachusetts: A. Wesley, 1992. $269 \mathrm{p}$. 